\title{
Gender differences in subjective memory impairment in a general population: the HUNT study, Norway
}

Jostein Holmen ${ }^{1 *}$, Ellen Melbye Langballe ${ }^{2}$, Kristian Midthjell ${ }^{1}$, Turid Lingaas Holmen ${ }^{1}$, Arvid Fikseaunet ${ }^{3}$, Ingvild Saltvedt ${ }^{4,5}$ and Kristian Tambs ${ }^{2}$

\begin{abstract}
Background: There is increased focus on early diagnosis of dementia, and subjective awareness of memory impairment is often assumed to be an early symptom of dementia. Subjective memory impairment (SMI) is used to describe subjective awareness of memory problems in the elderly after identifiable diseases which include this symptom are excluded. The aim of the present cross-sectional study was to examine the occurrence of SMI in a general adult population and its association with education level, subjective health, anxiety, depression and satisfaction with life.

Methods: Nine items about memory were included in the questionnaire for participants aged $30+$ in the large population based HUNT Study(2006-08). Health data, such as global health, symptoms of anxiety and depression and satisfaction with life in addition to level of education was collected. Stratified analyses were used to study gender differences in SMI sum score. Cohen's d was measured as an effect size. One-way ANOVA followed by a Tukey post-hoc test was used to test the association between SMI sum score and each category of gender, age, education, global health and satisfaction with life. Bivariate correlation between symptoms of anxiety and depression and SMI were tested and finally the association between SMI sum score and age, gender, education level, subjective health and symptoms of depression and anxiety was tested in a linear regression model.
\end{abstract}

Results: Nearly half of the participants ( $n=37,405: 44.6 \%$ women, $46.2 \%$ men) reported minor memory problems. Severe problems were reported by $1.2 \%$ of women and $1.6 \%$ of men. Remembering names and dates were the most frequent problems, and they increased with age. In eight out of nine items, more men than women reported memory problems. Elevated SMI was associated with poor self-perceived global health, symptoms of anxiety and depression and low education in both men and women and in all age groups.

Conclusion: Minor subjective memory problems were very common, and SMI was clearly associated with health measures and with level of education. The relatively strong association between SMI and symptoms of depression might be of clinical interest. The reason for men reporting more memory problems than women remains unexplained.

Keywords: Subjective memory impairment (SMI), Prevalence, Gender differences, Population study, Wide age range, Education, Perceived health, Anxiety, Depression, Satisfaction with life

\footnotetext{
* Correspondence: jostein.holmen@ntnu.no

${ }^{1}$ HUNT Research Centre, Department of General Practice and Public Health,

Norwegian University of Science and Technology (NTNU), HUNT

forskningssenter, Forskningsvegen 2, 7600 Levanger, Norway

Full list of author information is available at the end of the article
} 


\section{Background}

There is increased focus on early diagnosis of dementia, and subjective awareness of memory impairment is often assumed to be an early symptom of dementia. Subjective memory impairment (SMI) is used to describe subjective awareness of memory problems in the elderly after identifiable diseases which include this symptom are excluded. Recent studies have demonstrated changed glucose metabolism and changes in hippocampus, in cerebrospinal fluid, in grey matter volume and in the occurrence of subcortical white matter lesions in SMI, thus indicating an association between SMI and early Alzheimer pathology (Scheef et al. 2012; Stewart et al. 2011).There is, however, no standardized definition of SMI. A related condition, amnestic Mild Cognitive Impairment (aMCI), is subjective memory loss confirmed by close relatives and neuropsychological assessment. Patients with aMCI perform normally in daily living, and therefore do not meet the diagnostic criteria for dementia (Morris et al. 2001; Petersen et al. 1999). However, aMCI has been shown to be an early manifestation of dementia. Therefore, the terms SMI and aMCI are related, except for the difference of SMI expressing subjective memory problems while aMCI includes objective confirmation of impaired memory. Unfortunately, there is no universal agreement on how to measure SMI, and the prevalence in various studies are highly dependent on the methods applied (Abdulrab \& Heun 2008). Some studies have used only one single item, while others have used a number of items (Abdulrab \& Heun 2008; Mitchell 2008). Most studies have focused on elderly people; very few have included age groups under 50 (Stewart 2012). The associations between SMI and anxiety and depression have been demonstrated in previous studies (Balash et al. 2013; Slavin et al. 2010).

In the third wave of the population based NordTrøndelag Health Study (The HUNT Study) performed in 2006-08 (HUNT3), questions designed to tap SMI were included as were various health related items that measured anxiety, depression, global health and satisfaction with life (Krokstad et al. 2013). The prevalence of SMI in a general population has not been thoroughly described in the literature, and the present study was designed to rectify that with a cross-sectional examination of the occurrence of self-reported, subjective memory impairment in a general adult population and its association with global health, anxiety, depression, satisfaction with life and level of education.

\section{Methods}

\section{Study population}

Nord-Trøndelag (130,000 inhabitants), one of 19 counties in Norway, is geographically situated in the central part of the country. In the third survey of the HUNT
Study (HUNT3), conducted from October 2006 to June 2008, all citizens in the county 20 years old and older $(\mathrm{n}=93,860)$ were invited to participate, of which 50,807 (54.1\%) attended (Krokstad et al. 2013). Data were obtained using several questionnaires, clinical examination and blood and urine samples. The personal invitations were sent out with a questionnaire (Q1) to be filled in and returned at one of the health examination sites. Another questionnaire (Q2) was handed out at attendance, completed at home and returned in the enclosed prepaid envelope. There were group specific versions of the questionnaire for men and women and the age groups 30-69 and 70+. All HUNT data are linked to the unique 11-digit identification number assigned to every Norwegian citizen at birth, enabling individual data linkage and linkage to national registers.

\section{Measures}

The Metamemory Questionnaire (MMQ), which was originally developed for the NORA-Study (Fromholdt \& Berg 1997), was included in Q2 for the age groups 30-69 and 70+. The MMQ has nine items about memory problems. The two first items asked about memory capacity in general: "Do you have problems with your memory?" and "Has your memory changed since you were younger?" The response categories were "no", "yes, some", and "yes, a lot". The following seven items asked about specific memory tasks: "Do you have problems remembering...": “.. what happened a few minutes ago", ".. the names of other people", ".. dates", ".. to carry out planned activities", “.. what happened a few days ago". ".. what happened some years ago" and "Do you have problems keeping track of a conversation". Response categories for these seven items were "never", "sometimes", and "often".

Global health was measured with the question, "How is your health at the moment?" and the four response categories were "very good", "good", "not so good" and "poor". Depression and anxiety symptoms were measured with the Hospital Anxiety and Depression Scale (HADS), consisting of seven items measuring anxiety and seven items measuring depression symptoms (Stordal et al. 2001; Mykletun et al. 2001). Satisfaction with life was measured with the item, "Thinking about your life at the moment, would you say that you by and large are satisfied with life, or are you mostly dissatisfied?" The seven response alternatives ranged from "very satisfied" to "very dissatisfied". Data on education were acquired from (Statistics Norway 2012) and categorized into three levels of highest education achieved: 1) Up to ten years, 2) up to thirteen years (three years in college/university), and 3) more than three years in college/university.

The participation in the HUNT Study was voluntary, and all participants signed an informed consent form. HUNT3 was approved by the Regional Committee for 
Medical and Health Research Ethics (REC), the Data Inspectorate and the Directorate of Health. The present study was also approved by REC.

\section{Statistics}

In total, 79,576 individuals in the age group 30+ were invited to the HUNT3 survey, and 46,289 (58.2\%) attended the health examination with completed Q1 (Krokstad et al. 2013). Out of these, 41,205 individuals (51.8\%) returned Q2 (2013), and 35,319 had filled in all nine SMI items. SPSS Missing Value Analysis (MVA) was used to impute values for the 2097 participants who had not answered between one and four SMI items, which resulted in 37,405 individuals providing SMI data for the analyses. If there were more than four unanswered SMI items, it was treated as missing data (Table 1). A sum score was created with the sum of answers of the nine SMI items, and these were coded 1 (no problem), 2 (some) or 3 (great/often problems), giving a sum score in the range of 9-27. Gender stratified analyses using 95\% Confidence Intervals were used to study gender differences in SMI sum score, and Cohen's d was measured as effect size. Oneway ANOVA followed by a Tukey post-hoc test was used to test the association between SMI sum score and each category of gender, age, education, global health and satisfaction with life. The depression (HADS-D) and anxiety (HADS-A) items of the HADS questionnaire were scored as summative indices, nine items in each. The correlations between anxiety (HADS-A) and depression (HADS-D) and the SMI items were calculated using Pearsons correlation coefficient. The distribution of the sum score was regarded as normally distributed and used as dependent variable in a linear regression model. According to the aim of the study we included the following variables in the model: Age, gender, education level, subjective health, symptom score of anxiety (HADS-A), symptom score of depression (HADS-D) and general satisfaction with life. The interaction terms, i.e. products of gender and each of the other variables, were also tested.
In a separate analysis, to test the effect of cardiovascular risk and diseases on the gender differences in SMI, we also included the following cardiovascular related variables: Having experienced myocardial infarction, angina pectoris, cerebral stroke or diabetes, and measures of total cholesterol, body mass index, waist/hip ratio, daily smoking and physical exercise. SPSS (Statistical Package for Social Sciences) version 19.0 was applied in the analyses, and $\mathrm{p}<0.05$ was considered statistically significant.

\section{Results}

Nearly half of the HUNT3 participants reported memory problems (item 1), while only $1.2 \%$ of women and $1.6 \%$ of men reported having more severe problems (Table 2). Of the nine SMI items, the most common complaints (sometimes or often) were remembering names (item 4) $(89.7 \%$ of the men, $86.5 \%$ of the women) and dates (item 5) (74.9\% of the men, $64.7 \%$ of the women). About $65 \%$ reported some change in memory ability since when they were younger (item 2), and $6.0 \%$ of women and $6.8 \%$ of men reported severe changes, which is about the same prevalence as was reported about remembering things that happened years ago (item 8). The least reported complaints were following a conversation (item 9) and remembering things that happened a few minutes ago (item 3).

Most memory complaints increased by age, but even in the youngest age groups many reported memory complaints (Table 2). In age group 30-39, 61.4\% of women and $60.1 \%$ of men reported problems remembering other people's names sometimes, and $11.8 \%$ of women and $18.6 \%$ of men often. The steepest age gradient was reported on item 2 (memory changes since younger) and on item 1 (problems with memory). The least steep age gradient was on item 6 (remembering something you have planned to do) in women and on item 5 (remembering dates) in men.

In general, men reported memory complaints more often than women. This was the case in eight out of the nine SMI items, and in most age groups (Table 3).

Table 1 Participation in the HUNT3 survey (2006-08) aged 30+, and individuals with valid data on subjective memory impairment (SMI) after imputation, by age and gender

\begin{tabular}{|c|c|c|c|c|c|c|c|c|c|c|c|c|c|c|c|}
\hline \multirow[b]{3}{*}{ Age } & \multicolumn{5}{|c|}{ Women } & \multicolumn{5}{|c|}{ Men } & \multicolumn{5}{|c|}{ Total } \\
\hline & \multirow{2}{*}{$\begin{array}{c}\text { Invited } \\
\mathbf{n}\end{array}$} & \multicolumn{2}{|c|}{ Participated $^{a}$} & \multicolumn{2}{|c|}{ Valid SMI data $^{b}$} & \multirow{2}{*}{$\begin{array}{c}\text { Invited } \\
n\end{array}$} & \multicolumn{2}{|c|}{ Participated $^{\mathrm{a}}$} & \multicolumn{2}{|c|}{ Valid SMI data $^{\mathrm{b}}$} & \multirow{2}{*}{$\begin{array}{c}\text { Invited } \\
\mathrm{n}\end{array}$} & \multicolumn{2}{|c|}{ Participated $^{\mathrm{a}}$} & \multicolumn{2}{|c|}{ Valid SMI data } \\
\hline & & $n$ & $\%$ & $n$ & $\%^{\mathrm{c}}$ & & $\mathrm{n}$ & $\%$ & $n$ & $\%^{\mathrm{c}}$ & & $n$ & $\%$ & $n$ & $\%^{c}$ \\
\hline $30-39$ & 7832 & 4019 & 51.3 & 3107 & 39.7 & 7914 & 2862 & 36.2 & 1877 & 23.7 & 15746 & 6881 & 43.7 & 4984 & 31.7 \\
\hline 40-49 & 8524 & 5447 & 63.9 & 4459 & 52.3 & 9212 & 4557 & 49.5 & 3348 & 36.3 & 17736 & 10004 & 56.4 & 7807 & 44.0 \\
\hline $0-59$ & 8415 & 5991 & 71.2 & 5033 & 59.8 & 8898 & 5418 & 60.9 & 4350 & 48.9 & 17313 & 11409 & 65.9 & 9383 & 54.2 \\
\hline $60-69$ & 6892 & 5137 & 74.5 & 4495 & 65.2 & 6909 & 4674 & 67.7 & 3969 & 57.4 & 13801 & 9811 & 71.1 & 8464 & 61.3 \\
\hline 70-79 & 4583 & 3080 & 67.2 & 2612 & 57.0 & 4011 & 2664 & 66.6 & 2287 & 57.0 & 8594 & 5744 & 66.8 & 4899 & 57.0 \\
\hline $80+$ & 4056 & 1439 & 35.5 & 1086 & 26.8 & 2330 & 1001 & 43.0 & 782 & 33.6 & 6386 & 2440 & 38.2 & 1868 & 29.3 \\
\hline Total & 40302 & 25113 & 62.3 & 20792 & 51.6 & 39274 & 21176 & 53.9 & 16613 & 42.3 & 79576 & 46289 & 58.2 & 37405 & 47.0 \\
\hline
\end{tabular}

a Participated by returning answered Q1. ${ }^{b}$ Valid data on all nine SMI questions after imputation. ${ }^{\mathrm{c}}$ Per cent of invited. 
Table 2 Prevalence of nine items of self-reported subjective memory impairment (SMI) by age; HUNT3 (2006-08)

\begin{tabular}{|c|c|c|c|c|c|c|c|c|c|c|c|c|c|c|c|c|c|c|}
\hline & \multicolumn{2}{|c|}{$\begin{array}{l}\text { (i1) Problems } \\
\text { with } \\
\text { memory (\%) }\end{array}$} & \multicolumn{2}{|c|}{$\begin{array}{l}\text { (i2) Memory } \\
\text { changed (\%) }\end{array}$} & \multicolumn{2}{|c|}{$\begin{array}{c}\text { (i3) Probl } \\
\text { remember } \\
\text { minutes } \\
\text { ago (\%) }\end{array}$} & \multicolumn{2}{|c|}{$\begin{array}{l}\text { (i4) Probl } \\
\text { remember } \\
\text { names (\%) }\end{array}$} & \multicolumn{2}{|c|}{$\begin{array}{l}\text { (i5) Probl } \\
\text { remember } \\
\text { dates }(\%)\end{array}$} & \multicolumn{2}{|c|}{$\begin{array}{l}\text { (i6) Probl } \\
\text { remember } \\
\text { plans (\%) }\end{array}$} & \multicolumn{2}{|c|}{$\begin{array}{l}\text { (i7) Probl } \\
\text { remember } \\
\text { days ago (\%) }\end{array}$} & \multicolumn{2}{|c|}{$\begin{array}{c}\text { (i8) Probl } \\
\text { remember } \\
\text { years ago (\%) }\end{array}$} & \multicolumn{2}{|c|}{$\begin{array}{l}\text { (i9) Probl } \\
\text { keeping } \\
\text { track of } \\
\text { conversation (\%) }\end{array}$} \\
\hline & Some & Great & Some & Great & Sometimes & Often & Sometimes & Often & Sometimes & Often & Sometimes & Often & Sometimes & Often & Sometimes & Often & Sometimes & Often \\
\hline \multicolumn{19}{|c|}{ Women } \\
\hline Age & $n=9366$ & $n=251$ & $n=13850$ & $n=1269$ & $n=4060$ & $n=231$ & $n=15102$ & $n=2989$ & $n=12048$ & $n=1446$ & $n=5207$ & $n=255$ & $n=6688$ & $n=408$ & $n=12916$ & $\mathrm{n}=1590$ & $n=4786$ & $n=332$ \\
\hline 30-39 & 29.4 & 1.0 & 40.3 & 2.9 & 11.8 & 0.5 & 61.4 & 11.8 & 50.5 & 6.3 & 26.5 & 1.8 & 24.9 & 1.9 & 53.6 & 7.3 & 20.6 & 1.5 \\
\hline $40-49$ & 35.7 & 1.4 & 55.5 & 4.2 & 14.9 & 0.7 & 70.0 & 12.8 & 56.0 & 6.0 & 26.7 & 1.0 & 29.0 & 2.0 & 61.0 & 7.1 & 22.2 & 1.6 \\
\hline 50-59 & 43.4 & 1.3 & 70.9 & 5.3 & 16.8 & 0.8 & 75.7 & 12.2 & 58.3 & 6.2 & 23.4 & 0.8 & 31.3 & 1.5 & 64.0 & 7.2 & 22.8 & 1.3 \\
\hline $60-69$ & 55.6 & 0.9 & 77.8 & 7.6 & 22.3 & 1.1 & 77.3 & 16.1 & 62.5 & 7.2 & 23.8 & 0.8 & 36.0 & 1.7 & 67.5 & 7.8 & 22.9 & 1.3 \\
\hline $70-79$ & 55.8 & 0.8 & 80.5 & 7.9 & 30.1 & 2.0 & 74.8 & 17.7 & 61.1 & 7.6 & 24.2 & 1.6 & 37.9 & 1.9 & 62.2 & 8.5 & 25.3 & 1.8 \\
\hline 80-89 & 56.8 & 2.5 & 74.4 & 14.4 & 35.7 & 4.1 & 69.3 & 21.5 & 57.2 & 13.5 & 28.8 & 3.7 & 40.0 & 5.4 & 59.1 & 10.5 & 29.3 & 3.8 \\
\hline Mean & 44.6 & 1.2 & 66.0 & 6.0 & 19.5 & 1.1 & 72.2 & 14.3 & 57.8 & 6.9 & 25.0 & 1.2 & 32.2 & 2.0 & 62.1 & 7.6 & 23.0 & 1.6 \\
\hline \multicolumn{19}{|c|}{ Men } \\
\hline Age & $\mathrm{n}=7732$ & $n=272$ & $n=10603$ & $n=1136$ & $n=4501$ & $n=305$ & $n=11427$ & $\mathrm{n}=3516$ & $n=10586$ & $n=1886$ & $n=6081$ & $n=293$ & $n=7284$ & $n=529$ & $n=10384$ & $n=1472$ & $n=4314$ & $n=287$ \\
\hline $30-39$ & 29.0 & 1.4 & 33.0 & 3.0 & 17.2 & 0.7 & 60.1 & 18.6 & 55.2 & 9.6 & 35.2 & 1.9 & 34.3 & 2.1 & 55.4 & 7.9 & 20.4 & 1.3 \\
\hline $40-49$ & 33.6 & 1.4 & 49.5 & 3.8 & 20.5 & 0.9 & 66.9 & 18.7 & 62.0 & 9.6 & 37.5 & 1.8 & 38.5 & 3.2 & 60.2 & 8.4 & 22.8 & 1.4 \\
\hline 50-59 & 43.4 & 1.7 & 66.5 & 5.2 & 23.8 & 1.7 & 69.3 & 21.0 & 64.1 & 10.7 & 36.2 & 1.8 & 42.6 & 3.1 & 62.5 & 8.8 & 25.3 & 1.7 \\
\hline $60-69$ & 55.4 & 1.5 & 75.4 & 7.6 & 30.7 & 2.0 & 71.1 & 22.4 & 65.9 & 12.5 & 35.1 & 1.0 & 46.0 & 2.7 & 66.4 & 8.8 & 26.7 & 1.7 \\
\hline $70-79$ & 62.0 & 1.5 & 78.5 & 11.6 & 38.5 & 2.9 & 72.2 & 22.4 & 69.0 & 13.0 & 367 & 1.6 & 52.2 & 4.0 & 65.1 & 9.8 & 30.6 & 2.1 \\
\hline 80-89 & 63.1 & 3.6 & 73.0 & 18.7 & 44.1 & 5.5 & 68.2 & 27.1 & 60.9 & 16.0 & 44.8 & 5.1 & 53.2 & 6.1 & 61.2 & 12.6 & 39.0 & 3.2 \\
\hline Mean & 46.2 & 1.6 & 63.4 & 6.8 & 27.0 & 1.8 & 68.6 & 21.1 & 63.6 & 11.3 & 36.6 & 1.8 & 43.8 & 3.2 & 62.5 & 8.9 & 26.0 & 1.7 \\
\hline
\end{tabular}


However, more women than men reported that their memory had changed (some) since they were younger (item 2). Mean SMI sum score in women was 13.86 (95\% CI 13.82-13.90) compared to 14.54 (95\% CI 14.1314.20) in men, increasing with age (Table 3). SMI sum score in both genders decreased with increasing educational level and decreased with improving global health and with improving satisfaction with life (Additional file 1: Figures S1, S2, S3 and S4). Though the gender differences were consistent through all strata and statistically significant, Cohen's d indicated that the effect size was small (Table 3). One-way ANOVA confirmed a statistically significant association $(\mathrm{p}<.001)$ with SMI sum score and gender, age, education level, global health and satisfaction with life, and a Tukey post-hoc test revealed that the SMI sum score was significantly different $(\mathrm{p}<.001)$ in each and every category of age, education level, global health, and satisfaction with life (data not shown).
Anxiety symptoms, measured as the sum score in HADS-A, was positively correlated with the SMI sum score and with each of the SMI items (Table 4). A similar association was found for symptoms of depression, measured as the sum score in HADS-D, and depression was more strongly correlated with SMI sum score than was HADS-A. In a linear regression model both HADS-D, age, HADS-A, gender, global health and education level were significantly associated with SMI sum score, while satisfaction with life was not (Table 5 ). When testing interaction terms, i.e. products of gender and each of the other variables, we found all to be highly significant $(\mathrm{p}<.001)$. Including cardiovascular related variables (having experienced myocardial infarction, angina pectoris, stroke or diabetes, total cholesterol, body mass index, waist/hip ratio, daily smoking, physical exercise) in the regression model did not change the beta of the gender association substantially (data not shown).

Table 3 SMI sum score (mean, SD, $95 \% \mathrm{Cl}$ and Cohen's d) by sex and age, education level, global health and satisfaction with life; HUNT3 (2006-08)

\begin{tabular}{|c|c|c|c|c|c|c|c|}
\hline \multirow[b]{3}{*}{ Age } & \multicolumn{3}{|c|}{ Women } & \multicolumn{3}{|c|}{ Men } & \multirow[b]{3}{*}{ Cohen's d } \\
\hline & \multicolumn{3}{|c|}{ SMI sum score } & \multicolumn{3}{|c|}{ SMI sum score } & \\
\hline & $n$ & Mean & SD 95\% Cl & $\mathrm{n}$ & Mean & SD 95\% Cl & \\
\hline 30-39 & 3107 & 12.89 & 2.98 12.79-13.00 & 1877 & 13.32 & $3.0413 .18-13.45$ & 0.14 \\
\hline $40-49$ & 4459 & 13.44 & $3.0013 .35-13.53$ & 3348 & 13.90 & $3.1013 .80-14.00$ & 0.15 \\
\hline $50-59$ & 5033 & 13.80 & $2.8913 .71-13.88$ & 4350 & 14.46 & $3.1114 .37-14.55$ & 0.22 \\
\hline $60-69$ & 4495 & 14.35 & $2.8614 .26-14.44$ & 3969 & 14.95 & 3.07 14.85-15.04 & 0.20 \\
\hline $70-79$ & 2612 & 14.54 & $3.0114 .40-14.63$ & 2287 & 15.43 & $3.0915 .31-15.55$ & 0.30 \\
\hline $80+$ & 1086 & 15.10 & $3.5114 .92-15.28$ & 782 & 16.04 & $3.4915 .83-16.26$ & 0.27 \\
\hline Mean & 20792 & 13.86 & $3.0313 .82-13.90$ & 16613 & 14.54 & $3.1914 .13-14.20$ & 0.22 \\
\hline \multicolumn{8}{|l|}{ Education level } \\
\hline Low & 4832 & 14.38 & $3.2114 .29-14.46$ & 3155 & 15.08 & $3.3414 .98-15.19$ & 0.22 \\
\hline Medium & 10060 & 13.95 & 2.97 13.89-14.01 & 9630 & 14.66 & $3.1814 .60-14.72$ & 0.23 \\
\hline High & 5859 & 13.28 & $2.8713 .20-13.36$ & 3800 & 13.80 & $2.9313 .70-13.90$ & 0.18 \\
\hline \multicolumn{8}{|l|}{ Global health } \\
\hline Poor & 281 & 15.96 & $4.0515 .61-16.31$ & 226 & 17.29 & $4.1016 .90-17.68$ & 0.33 \\
\hline Not so good & 5643 & 14.93 & $3.2614 .85-15.01$ & 3743 & 15.73 & $3.4215 .64-15.83$ & 0.24 \\
\hline Good & 11039 & 13.59 & 2.78 13.54-13.65 & 9763 & 14.36 & $2.9614 .30-14.42$ & 0.27 \\
\hline Very good & 2922 & 12.56 & $2.4912 .45-12.67$ & 2317 & 13.05 & $2.7212 .93-13.17$ & 0.19 \\
\hline \multicolumn{8}{|l|}{ Satisfied with life } \\
\hline Extremely satisfied & 4161 & 13.09 & $2.8213 .00-13.18$ & 3215 & 13.81 & $3.1613 .71-13.92$ & 0.24 \\
\hline Very satisfied & 7316 & 13.49 & 2.77 13.42-13.56 & 6142 & 14.15 & 2.91 14.07-14.22 & 0.23 \\
\hline Quite satsified & 6220 & 14.28 & $3.0614 .20-14.36$ & 4993 & 14.93 & $3.1114 .84-15.01$ & 0.21 \\
\hline So and so & 2289 & 14.92 & $3.2614 .80-15.04$ & 1583 & 15.79 & 3.55 15.64-15.93 & 0.26 \\
\hline Rather dissatisfied & 222 & 15.82 & $3.9215 .43-16.22$ & 207 & 16.52 & $4.0116 .11-16.93$ & 0.18 \\
\hline Very dissatisfied & 82 & 16.55 & $3.9015 .89-17.20$ & 75 & 17.17 & 4.19 16.49-17.86 & 0.15 \\
\hline Extremely dissatisfied & 40 & 16.10 & $5.0215 .16-17.04$ & 39 & 16.59 & 4.58 15.64-17.54 & 0.10 \\
\hline
\end{tabular}


Table 4 Bivariate correlation between anxiety (HADS-A) and depression (HADS-D) measured by the Hospital Anxiety and Depression Symptom Scale (HADS) and the Subjective Memory Impairment (SMI) items; HUNT3 (2006-08)

\begin{tabular}{|c|c|c|c|c|}
\hline \multirow{3}{*}{$\begin{array}{l}\text { Subjective memory impairment } \\
\text { (SMI) items } \\
\text { i1. Problems with your memory }\end{array}$} & \multicolumn{4}{|c|}{ Pearson correlation coefficient ( $p$ value) } \\
\hline & \multicolumn{2}{|c|}{ HADS-A } & \multicolumn{2}{|c|}{ HADS-D } \\
\hline & 0.226 & $<0.01$ & 0.288 & $<0.01$ \\
\hline i2. Changed since you were younger & 0.177 & $<0.01$ & 0.288 & $<0.01$ \\
\hline \multicolumn{5}{|l|}{ Do you have trouble remembering: } \\
\hline i3. - what happened few minutes ago & 0.192 & $<0.01$ & 0.254 & $<0.01$ \\
\hline i4. - names of other people & 0.146 & $<0.01$ & 0.204 & $<0.01$ \\
\hline i5. - dates & 0.160 & $<0.01$ & 0.217 & $<0.01$ \\
\hline i6. - to carry out planned activities & 0.209 & $<0.01$ & 0.254 & $<0.01$ \\
\hline i7. - what happened few days ago & 0.194 & $<0.01$ & 0.263 & $<0.01$ \\
\hline i8. - what happened years ago & 0.154 & $<0.01$ & 0.189 & $<0.01$ \\
\hline i9. - keeping track of a conversation & 0.259 & $<0.01$ & 0.287 & $<0.01$ \\
\hline SMI sum score & 0.290 & $<0.01$ & 0.381 & $<0.01$ \\
\hline
\end{tabular}

\section{Discussion}

The present study supports previous studies (Cooper et al. 2011) in which self-perceived memory problems were shown to be widespread in the general population, occurring in all age groups and both genders. Most people reported only minor problems while a few reported more severe problems in our study. Though the problems increased with age, many younger people reported memory problems. Memory problems were reported more often in men than in women and were associated with global health, symptoms of depression and anxiety and level of education.

One strength of the present study was the number and variety of items that measured different dimensions of memory problems and the number of response categories (Fromholdt \& Berg 1997). Another strength was the setting: the SMI items were part of a general health survey collecting a large number of other relevant health data, but without specific focus on cognitive impairment. In addition, the entire, unselected population was invited covering a wide age range, and the number of participants was higher than in other studies.

The participation of the HUNT Study presupposed relatively high cognitive function being that the participants must read information folders, sign the consent form and fill in several questionnaires, yet in this study we could not include an objective measurement of cognitive function. Though the non-participation study demonstrated that the participants were in general healthier than the non-participants (Langhammer et al. 2012), some participants could have had mild, or perhaps severe, cognitive impairment. In a later, separate survey of cognitive impairment in the county, a total of 222 individuals with dementia were later found to have participated in HUNT3 (Bergh S, personal communication). However, the relatively few, mostly elderly, individuals with impaired cognitive function could not change the over-all pattern of SMI in the population.

The age gradient in the present study is consistent with most other studies (Iliffe \& Pealing 2010), but some studies did not find an increase with age (Cooper et al. 2011). A typical feature in the present study was that most people reported "some" problems and "sometimes" having these problems; this was the case even in the younger age groups, reflecting that memory problems are among the everyday complaints in modern society. Our data did not reveal whether such complaints have any clinical significance. It might, however, be reasonable to suggest that memory problems are experienced differently in different age groups, and perhaps younger

Table 5 Linear regression model: The association between SMI sum score (as dependent variable) and age, gender, education level, subjective health and symptoms of depression and anxiety; HUNT3 (2006-08)

\begin{tabular}{lcccc}
\hline Model & Unstandardized coefficients B & 95\% Confidence interval for B & Standardized coefficients Beta & Sig. $\mathbf{p}$ \\
\hline Sum depression score (HADS-D) & $.231(.007)$ & $.218-.244$ & .217 & .149 \\
Age & $.034(.001)$ & $.032-.036$ & $<0.01$ \\
Sum anxiety score (HADS-A) & $.154(.006)$ & $.142-.165$ & .163 & .03 \\
Gender & $.679(.031)$ & $.619-.740$ & $<01$ \\
How is your health at present & $(-) .500(.025)$ & $(-) .550-(-) .451$ & $(-) .107$ & $<0.01$ \\
Highest education level & $(-) .094(.023)$ & $(-) .140-(-) .048$ & $<.01$ & $<01$ \\
\hline
\end{tabular}


people with more cognitively demanding daily life are more inclined to report memory problems than elderly people with a calmer life situation (Gino et al. 2010). Relatively few people reported more severe problems, and even if these problems are associated with increased risk of cognitive impairment and dementia (Mitchell 2008), the strength of this association can only be revealed in prospective studies.

Only a few studies have reported gender differences in SMI, and most of them have either found no difference or a higher prevalence in women (Iliffe \& Pealing 2010; Genziani et al. 2013). However, in a large Australian Study (Paradise et al. 2011), men reported more memory problems, which is in accordance with the present study: men consistently reported memory problems more often than women in eight out of nine SMI items and a gender difference was demonstrated in nearly all age groups (Table 5). One exception was item 2 (changes in memory since younger age), where women in most age groups reported more changes than men. One hypothesis explaining the gender differences might be that lower participation rate in men introduced selection bias, i.e. that participating men were more willing to report memory problems than non-participating men. However, an extensive non-participation study (Langhammer et al. 2012) demonstrated that participants reported better subjective health, less mental stress and insomnia, had sought less help for mental health, reported less cardiovascular diseases and had lower mortality compared to non-participants. This was the case in both genders. The non-participation study did not include the SMI questions, but in the data there is no evidence that participants were more motivated or more willing to report health problems compared to non-participants, rather the opposite.

Another possible hypothesis is that the gender differences might be associated with cardiovascular diseases or risk factors, for which similar gender differences are observed. Elevated blood pressure, dyslipidemia, smoking, physical inactivity, elevated body mass index or other factors inducing cerebral microvascular damages or neurodegeneration might be more prevalent in men than in women, explaining why men have more memory problems than women. However, including cardiovascular related variables into the linear regression model in the present data set did not change the gender association with the SMI sum score substantially. In a previous paper from the same HUNT population it was demonstrated a clear associations between stroke and heart disease and higher levels of SMI, otherwise strong positive relationships between cardiovascular risk factors and SMI were not found (Langballe et al. 2012). As a conclusion, there is no evidence in our data that the different cardiovascular risk can explain the gender differences in SMI.
One might speculate that the higher prevalence of memory problems in men reflects a more cognitively demanding life for men than for women. However, in Norway $70-80 \%$ of the female workforce is employed, the highest employment rate for women in the world, and there is no evidence that Norwegian women have less cognitively demanding lives than Norwegian men (Koren 2012). The same gender difference is observed in the elderly and retired age groups, which also makes this explanation unlikely. In conclusion, the gender difference remains unexplained.

Though the clinical significance of the reported memory problems cannot be revealed in this cross-sectional study, the memory problems were clearly shown to be associated with a number of health measures. In accordance with previous studies, SMI in the present study was associated with depressive symptoms measured as a sum score of HADS (Stordal et al. 2001; Mykletun et al. 2007). Depression is associated with both cognitive impairment and dementia (Panza et al. 2010; Comijs et al. 2002), but whether SMI recorded in the present study was a result of depression or vice versa, is unknown. However, studies have demonstrated an association between improved mood and reduced memory complaints in depressed patients (Antikainen et al. 2001), and irrespective of the causeeffect relationship, this association could be of clinical importance. The association between SMI and anxiety found in the present study is in accordance with other results (Cooper et al. 2011; Comijs et al. 2002 Nov). Previous studies have demonstrated the association with self-reported health status (Cutler \& Grams 1988), which is consistent with the association with global health in the present study. In a bivariate analysis SMI was also associated with satisfaction with life. However, in a multivariate analysis, when the global health variable was introduced, the association disappeared, indicating that satisfaction with life strongly reflected global health. We cannot outline the cause-effect relationship in either of these cases, but the results clearly demonstrate that SMI measured in the HUNT Study was a relevant health measure. Several studies have indicated that SMI might be a precursor of aMCI and eventually dementia (Scheef et al. 2012; Stewart et al. 2011; Jessen et al. 2010; Jonker et al. 2000), suggesting that SMI might be of importance in recognizing early cognitive impairment. The findings in the present study should therefore be tested in other populations, and prospective studies might also reveal how important the recorded memory complaints are as precursors of impaired cognition.

\section{Conclusions}

This cross-sectional study demonstrates that when SMI was measured with the nine items of the Metamemory Questionnaire, minor problems were frequently reported, even in young age groups, but only a few reported severe 
memory problems. Memory problems increased with age, and in all age groups more men than women reported memory problems. Additionally, SMI was associated with self-perceived global health, symptoms of anxiety and depression and with level of education. The relatively strong association between SMI and symptoms of depression might be of clinical importance irrespective of cause-effect. Despite several hypotheses, the reason behind men reporting more memory problems than women remains unexplained.

\section{Additional file}

Additional file 1: Figure S1. Mean SMI sum score by age and gender; Figure S2 Mean SMI sum score by perceived global health and gender; Figure S3 Mean SMl sum score by education level and gender; Figure S4 Mean SMI sum score by general satisfaction with life and gender.

\section{Abbreviations}

HUNT: The Nord-Trøndelag health study, Norway (Helseundersøkelsen i Nord-Trøndelag), conducted in three surveys, HUNT1 (1984-86), HUNT2 (1995-97) and HUNT3 (2006-08); SMI: Subjective memory impairment; aMCl: Amnesic mild cognitive impairment; MMQ: The metamemory questionnaire; REC: The regional committee for medical and health research ethics; SPSS: Statistical package for social sciences; HADS: The hospital and anxiety depression scale; HADS-A: The hospital and anxiety depression scale, components measuring anxiety; HADS-D: The hospital and anxiety depression scale, components measuring depression.

\section{Competing interests}

The authors declare that they have no competing interests.

\section{Authors' contributions}

JH was PI of the HUNT Study 1984-2008 collected the data, initiated the present study, conducted the analyses and drafted the manuscript. EML contributed to the statistical analyses and drafting of the manuscript.KM and TLH contributed to the data collection and evaluated and revised the manuscript. AF, IS and KT evaluated and revised the manuscript. All authors read and approved the final manuscript.

\section{Acknowledgements}

The Nord-Trøndelag Health Study (the HUNT Study) is a collaboration between HUNT Research Centre (Faculty of Medicine, Norwegian University of Science and Technology NTNU), Nord-Trøndelag County Council, Central Norway Health Authority and the Norwegian Institute of Public Health.

\section{Author details}

${ }^{1}$ HUNT Research Centre, Department of General Practice and Public Health, Norwegian University of Science and Technology (NTNU), HUNT forskningssenter, Forskningsvegen 2, 7600 Levanger, Norway. ${ }^{2}$ Department of Mental Health, The Norwegian Institute of Public Health, Oslo, Norway. ${ }^{3}$ Levanger Hospital, The Nord-Trøndelag Health Authority, Levanger, Norway. ${ }^{4}$ Department of Neuroscience, Norwegian University of Science and Technology (NTNU), Trondheim, Norway. ${ }^{5}$ Department of Geriatrics, St Olav Hospital, University Hospital of Trondheim, Trondheim, Norway.

Received: 17 June 2013 Accepted: 14 October 2013 Published: 25 October 2013

\section{References}

(2012). Statistics Norway. http://www.ssb.no/. (2013). HUNT Data bank. http://www.ntnu.edu/hunt.

Abdulrab, K, \& Heun, R. (2008). Subjective memory impairment. A review of its definitions indicates the need for a comprehensive set of standardised and validated criteria. European Psychiatry, 23(5), 321-330.
Antikainen, R, Hanninen, T, Honkalampi, K, Hintikka, J, Koivumaa-Honkanen, H, Tanskanen, A, \& Viinamaki, H. (2001). Mood improvement reduces memory complaints in depressed patients. European Archives of Psychiatry and Clinical Neuroscience, 251(1), 6-11.

Balash, Y, Mordechovich, M, Shabtai, H, Giladi, N, Gurevich, T, \& Korczyn, AD. (2013). Subjective memory complaints in elders: depression, anxiety, or cognitive decline? Acta Neurologica Scandinavica, 127(5), 344-350.

Comijs, HC, Deeg, DJ, Dik, MG, Twisk, JW, \& Jonker, C. (2002). Memory complaints; the association with psycho-affective and health problems and the role of personality characteristics. A 6-year follow-up study. Journal of Affective Disorders, 72(2), 157-165.

Cooper, C, Bebbington, P, Lindesay, J, Meltzer, H, McManus, S, Jenkins, R, \& Livingston, G. (2011). The meaning of reporting forgetfulness: a cross-sectional study of adults in the English 2007 Adult Psychiatric Morbidity Survey. Age and Ageing, 40(6), 711-717.

Cutler, SJ, \& Grams, AE. (1988). Correlates of self-reported everyday memory problems. Journal of Gerontology, 43(3), S82-\$90.

Fromholdt, P, \& Berg, S. (1997). Self-reported memory and cognitive performance among 75-year old people from three Nordic Cities. In E Heikkinen, S Berg, M Schroll, B Steen, \& A Viidik (Eds.), Functional Status, Health and Aging, The NORA Study (Series: Facts, Research and Intervention) (pp. 55-65). Paris: Serdi Publishing Company.

Genziani, M, Stewart, R, Bejot, Y, Amieva, H, Artero, S, \& Ritchie, K. (2013). Subjective memory impairment, objective cognitive functioning and social activity in French older people: findings from the Three Cities study. Geriatrics and Gerontology International, 13(1), 139-145.

Gino, S, Mendes, T, Maroco, J, Ribeiro, F, Schmand, BA, de Mendonca, A, \& Guerreiro, M. (2010). Memory complaints are frequent but qualitatively different in young and elderly healthy people. Gerontology, 56(3), 272-277.

Iliffe, S, \& Pealing, L. (2010). Subjective memory problems. BMJ, 340, c1425.

Jessen, F, Wiese, B, Bachmann, C, Eifflaender-Gorfer, S, Haller, F, Kolsch, H, Luck, T, Mosch, E, van den Bussche, $H$, Wagner, M, Wollny, A, Zimmermann, $T$, Pentzek, M, Riedel-Heller, SG, Romberg, HP, Weyerer, S, Kaduszkiewicz, H, Maier, W, \& Bickel, H. (2010). Prediction of dementia by subjective memory impairment: effects of severity and temporal association with cognitive impairment. Archives of General Psychiatry, 67(4), 414-422.

Jonker, C, Geerlings, MI, \& Schmand, B. (2000). Are memory complaints predictive for dementia? A review of clinical and population-based studies. International Journal of Geriatric Psychiatry, 15(11), 983-991.

Koren, C. (2012). Kvinnenes rolle i norsk økonomi (Womens role in Norwegian economy). Oslo: Universitetsforlaget.

Krokstad, S, Langhammer, A, Hveem, K, Holmen, T, Midthjell, K, Stene, T, Bratberg, G, Heggland, J, \& Holmen, J. (2013). Cohort Profile: The HUNT Study, Norway. International Journal of Epidemiology, 42(4), 968-977.

Langballe, E, Tambs, K, Saltvedt, I, Midthjell, K, \& Holmen, J. (2012). The association between vascular factors and subjective memory impairment in older people: The HUNT Study, Norway. Norsk Epidemiologi, 22(2), 209-215.

Langhammer, A, Krokstad, S, Romundstad, P, Heggland, J, \& Holmen, J. (2012). The HUNT study: participation is associated with survival and depends on socioeconomic status, diseases and symptoms. BMC Medical Research Methodology, 12, 143.

Mitchell, AJ. (2008). The clinical significance of subjective memory complaints in the diagnosis of mild cognitive impairment and dementia: a meta-analysis. International Journal of Geriatric Psychiatry, 23(11), 1191-1202.

Morris, JC, Storandt, M, Miller, JP, McKeel, DW, Price, JL, Rubin, EH, \& Berg, L. (2001). Mild cognitive impairment represents early-stage Alzheimer disease. Archives of Neurology, 58(3), 397-405.

Mykletun, A, Bjerkeset, O, Dewey, M, Prince, M, Overland, S, \& Stewart, R. (2007). Anxiety, depression, and cause-specific mortality: the HUNT study. Psychosomatic Medicine, 69(4), 323-331.

Mykletun, A, Stordal, E, \& Dahl, AA. (2001). Hospital Anxiety and Depression (HAD) scale: factor structure, item analyses and internal consistency in a large population. The British Journal of Psychiatry, 179, 540-544

Panza, F, Frisardi, V, Capurso, C, D'Introno, A, Colacicco, AM, Imbimbo, BP Santamato, A, Vendemiale, G, Seripa, D, Pilotto, A, Capurso, A, \& Solfrizzi, V. (2010). Late-life depression, mild cognitive impairment, and dementia: possible continuum? The American Journal of Geriatric Psychiatry, 18(2), 98-116.

Paradise, MB, Glozier, NS, Naismith, SL, Davenport, TA, \& Hickie, IB. (2011). Subjective memory complaints, vascular risk factors and psychological distress in the middle-aged: a cross-sectional study. BMC Psychiatry, 11, 108. 
Petersen, RC, Smith, GE, Waring, SC, Ivnik, RJ, Tangalos, EG, \& Kokmen, E. (1999). Mild cognitive impairment: clinical characterization and outcome. Archives of Neurology, 56(3), 303-308.

Scheef, L, Spottke, A, Daerr, M, Joe, A, Striepens, N, Kolsch, H, Popp, J, Daamen, M, Gorris, D, Heneka, MT, Boecker, H, Biersack, HJ, Maier, W, Schild, HH, Wagner, M, \& Jessen, F. (2012). Glucose metabolism, gray matter structure, and memory decline in subjective memory impairment. Neurology, 79(13), 1332-1339.

Slavin, MJ, Brodaty, H, Kochan, NA, Crawford, JD, Trollor, JN, Draper, B, \& Sachdev, PS. (2010). Prevalence and predictors of "subjective cognitive complaints" in the Sydney Memory and Ageing Study. The American Journal of Geriatric Psychiatry, 18(8), 701-710.

Stewart, R. (2012). Subjective cognitive impairment. Current Opinion in Psychiatry, $25(6), 445-450$

Stewart, R, Godin, O, Crivello, F, Maillard, P, Mazoyer, B, Tzourio, C, \& Dufouil, C. (2011). Longitudinal neuroimaging correlates of subjective memory impairment: 4-year prospective community study. The British Journal of Psychiatry, 198(3), 199-205

Stordal, E, Bjartveit, KM, Dahl, NH, Krüger, O, Mykletun, A, \& Dahl, AA. (2001). Depression in relation to age and gender in the general population: the Nord-Trondelag Health Study (HUNT). Acta Psychiatrica Scandinavica, 104(3), 210-216.

doi:10.1186/2050-7283-1-19

Cite this article as: Holmen et al:: Gender differences in subjective memory impairment in a general population: the HUNT study, Norway. BMC Psychology 2013 1:19.

\section{Submit your next manuscript to BioMed Central and take full advantage of:}

- Convenient online submission

- Thorough peer review

- No space constraints or color figure charges

- Immediate publication on acceptance

- Inclusion in PubMed, CAS, Scopus and Google Scholar

- Research which is freely available for redistribution 